DOI: https: / / doi.org/10.53754/iscs.v1i1.4

\title{
MASLAHAH DALAM PERTIMBANGAN HUKUM HAKIM PADA PUTUSAN IZIN POLIGAMI NOMOR 0020/Pdt.G/2017/PA.MN
}

\section{UTILITY IN JUDGES' LEGAL CONSIDERATIONS ON POLYGAMY LICENSE DECISION NUMBER 0020/Pdt.G/2017/PA.MN}

\author{
Izzat Abdika Mukalafin \\ Institut Agama Islam Negeri Ponorogo \\ Email; kevinabdika36@gmail.com
}

\begin{abstract}
Maslahah actions that encourage human goodness or anything beneficial to human beings. This article is in the decision of the Religious Court of Madiun City number 0020/Pdt.G/2017/PA.Mn. The judge only granted the application for permission to have polygamy and rejected the application for separation of joint property; the decision was not granted on the verdict. The method used in this research is a qualitative research method that produces descriptive data analysis. Primary data in the form of the judge's decision of the Religious Court of Madiun City Number 0020/Pdt.G/2017/PA.Mn The secondary source of library materials in the form of books and interviews with judges. The results of this study there are three conclusions, namely 1). That is the decision with case number 0020/Pdt.G/2017/PA.Mn is by the rules of Maslahah Dzaruriyyah because in this matter, to preserve religion, soul, intellect, lineage, and property have been fulfilled. Only one thing has not been fulfilled about the property, so the more significant problem must come first. 2). The maslahah of formal and material written evidence has been met, but in the evidence of common property is not by the law, the judge rejected it, and it is by the maslahah mu'tabaroh supported by syara '. 3). The maslahah in the witness evidence, including the maslahah hajjiyah, is less than maximum, or it is still doubtful that the witness only knows it. Not by the material requirements (Article 171 $\mathrm{HIR} / 308 \mathrm{RBg}$ ) to see, hear, and experience for himself. So the judge gave relief to the parties to support the fulfilment of the maintenance of religion, soul, intellect, lineage and property.
\end{abstract}

Keywords: Maslahah, Judge's Consideration, Polygamy Decision

\section{PENDAHULUAN}

Poligami adalah ikatan perkawinan dalam hal mana suami mengawini lebih dari satu istri dalam waktu yang sama.(Hermanto, 2017) Perkataan poligami sendiri berasal dari bahasa yunani, yaitu polu yang berarti banyak dan gamein yang berati kawin. Jadi poligami adalah perkawinan yang banyak, atau dilndonesia terkenal dengan istilah permaduan.(Sugianto, 2017)

Polemik yang terjadi tidak terlepas dari apakah seorang laki-laki yang berpoligami mampu berbuat adil kepada istri-istrinya yang lebih dari satu. Islam mengajarkan, bahwa seorang laki-laki dapat menikah atau melakukan perkawinan lebih dari satu apabila seorang laki-laki mampu berbuat adil, dalam arti mampu memenuhi nafkah lahir-batin kepada istri- istrinya secara berimbang tanpa memihak salah satu istri,(Ardhian et al., 2015) dalam masyarakat juga banyak alasan yang yang menyebabkan seseorang melakukan poligami. Dari hal-hal yang kecil yang terkadang tidak dapat diterima dengan akal pikiran dan bertentangan dengan nilai keadilan dan persamaan hak antara laki-laki dan perempuan sampai kepada hal-hal yang memang diperbolehkan oleh syariat serta tidak menodai rasa keadilan dan hati nurani. Dan yang sering dijadikan alasan salah satunya adalah karena alasan tidak mampu memenuhi kewajiban sebagai seorang istri kepada suami. Berdasarkan Undang-Undang No 1 
Tahun 1974 pasal 4 ayat 2 Pengadilan hanya akan memberikan izin kepada seorang suami yang akan beristri lebih dari seorang apabila Istri tidak dapat menjalankan kewajibanya sebagai istri, Istri mendapat cacat badan atau penyakit yang tidak dapat disembuhkan, Istri tidak dapat melahirkan keturunan (Belakang, 1974).

Pengadilan Agama Kota Madiun memeriksa dan mengadili dalam tingkat pertama yang berada di wilayah Kota Madiun. Pada bulan Februari tahun 2017 Pengadilan Agama Kota Madiun telah memutus masalah perkara poligami dengan perkara Nomor 0020/Pdt.G/2017/PA.Mn.(Direktori Putusan Mahkamah Agung Republik Indonesia, 2017)

Dalam duduk perkara tidak disebutkan secara tegas bahwa alasan berpoligami adalah karena isteri pertama kurang bisa melayani pemohon dengan baik dengan alasan bekerja di luar negeri atau kebutuhan biologis pemohon yang tinggi, padahal pemohon mempunyai nafsu sex yang besar dan selama menikah pemohon dan termohon telah hidup rukun dan dikaruniai satu anak. Dari alasan tersebut mungkin hakim memiliki dasar lain dalam memutus perkara. Diantaranya kemaslahatan putusan tersebut dilihat dari kacamata maslahah disitu ada beberapa maslahah yang kurang terpenuhi.

Maslahah dalam kajian ushul fiqh adalah semakna dengan kata manfaat, yaitu bentuk masdar yang berarti baik dan mengandung manfaat. Maslahah merupakan bentuk mufrad (tunggal) yang jamaknya (plural) masalih. Dari makna kebahasaan ini dipahami bahwa maslahah meliputi segala yang mendatangkan manfaat, baik melalui cara mengambil dan melakukan suatu tindakan maupun dengan menolak dan menghindarkan segala bentuk yang menimbulkan kemadharatan dan kesulitan, adapun tujuan syara' dalam menetapkan hukum itu ada lima, yaitu: memelihara agama, jiwa, akal, keturunan, dan harta. (Muhamad Abu Zahrah, 2010)

Dalam putusan No.0020/Pdt.G/2017/PA.Mn berdasarkan pemahaman awal peneliti belum mencerminka adanya kemaslahatan karena hakim tidak mengabulkannya terkait harta bersama, serta disisi yang lain dalam pembuktian surat, terutama harta bersama surat belum sesuai hukum acara perdata di Pengadilan Agama dan tidak dileges pos kemudian pemohon tidak bisa membuktikanya. Pembuktian saksi dalam syarat materiil saksi kurang terpenuhi, saksi hanya lebih melihat tidak mendengar dan tidak mengalami sendiri. Majelis hakim Pengadilan Agama Kota Madiun mempunyai dasar hukum yang kuat dan alat bukti saksi dalam pertimbangan hukum tersendiri yang kuat, sehingga memutuskan untuk memberikan izin poligami kepada pemohon.(wawancara penanganan perkara, 2019) Oleh karena itu, penyusun merasa perlu untuk melakukan penelitian lebih lanjut untuk mendapatkan informasi dan pengetahuan lebih dalam mengenai dasar dan pertimbangan hukum yang digunakan hakim Pengadilan Agama Kota Madiun dalam mengabulkan permohonan izin poligami. Maka dari sini penulis beranggapan untuk menganalisi masalah ini dengan pisau analisis maslahah. 


\section{METODE}

Metode yang digunakan dalam penelitian ini adalah metode penelitian kualitatif yang menghasilkan data deskriptif analisis. Data dari penelitian ini adalah primer berupa putusan hakim Pengadilan Agama Kota Madiun Nomor 0020/Pdt.G/2017/PA.Mn Sumber sekundernya dari bahan pustaka berupa buku dan wawancara dengan hakim. Teknik analisis yang digunakan adalah analisis yuridis-normatif, yakni mengekplorasi isi, mengkomparasikan, dan mensitesa ketentuan dalam undang-undang, doktrin hukum dan sejenisnya dengan putusan hakim tentang poligami.

\section{PEMBAHASAN}

A. Unsur Maslahah Pada Perkara No.0020/Pdt.G/2017/Pa.Mn Sebagai Pertimbangan Hukum Hakim Dalam Perkara Poligami Di Pengadilan Agama Kota Madiun.

Dalam hal ini hakim adalah seseorang yang berpengaruh untuk mengambil tindakan atau putusan yaitu dengan mempertimbangkan keadilan, kemanfaatan serta kepastian hukum.(Adonara, 2015) Hakim Pengadilan Agama Kota Madiun pada tahun 2017 menangani perkara tentang poligami dengan Nomor putusan 0020/Pdt.G/2017/PA.Mn. (Direktori Putusan Mahkamah Agung Republik Indonesia, 2017)

Perkara ini bermula dari pemohon mengajukan permohonanya untuk melakukan poligami dengan beralasan istri bekerja diluar negeri dan suami kebutuhan biologisnya kurang terpenuhi. Calon isteri kedua berstastus janda cerai. Pemohon dan termohon merupakan istri yang sah yang dicatatkan di Kantor Urusan Agama (KUA). Selama menikah mereka dikaruniai 1 (satu) anak. Bahwa Pemohon mengajukan izin poligami ini, karena termohon (istri pertama) kurang bisa melayani pemohon dengan baik dengan alasan bekerja di luar negeri atau kebutuhan biologis Pemohon yang tinggi, padahal Pemohon mempunyai nafsu sex yang besar. Kemudian majlis hakim memutuskan atau mengadili :(Direktori Putusan Mahkamah Agung Republik Indonesia, 2017)

1. Mengabulkan permohonan pemohon sebagian;

2. Memberi izin kepada Pemohon (pemohon) untuk menikah lagi (yang kedua

3. dengan seorang wanita bernama (calon istri kedua binti Warsiyo alias Gunawan);

4. Menolak permohonan pemohon selain dan selebihnya;

5. Membebankan kepada pemohon untuk membayar biaya perkara sejumlah Rp 291.000,-(dua ratus sembilan puluh satu ribu rupiah)

Dalam memutuskan perkara ini hakim bertumpu kepada teks undang- undang artinya hakim hanya menerapkan serta menyamakan kejadian dengan undang-undang yang ada kemudian mengadili dengan melihat aspek keadilan dan juga kemudhorotan. (wawancara penanganan perkara, 2019)

Apabila dilihat dari pertimbangan hukum yang digunakan hakim, pada intinya izin 
poligami ini dikabulkanya hakim telah mempertimbangkan beberapa hal yaitu mendatangkan kemudahan dan tidak adanya kesulitah oleh para kedua belah pihak. Ada tiga maslahah dari segi tingkatanya tetapi hanya satu yang sesuai untuk menjawab rumusan masalah yang pertama yaitu Maslahah dzaruriyyah.

Maslahah dzaruriyyah (primer) yang dikandung oleh segala perbuatan dan tindakan yang tidak boleh tidak, demi tegaknya kehidupan manusia secara keseluruhan, terutama kelima jenis maslahah (memelihara agama, jiwa, akal budi, pemeliharaan kehormatan diri serta keturunan, dan harta kekayaan). (Muhamad Abu Zahrah, 2010)

Memelihara agama bagi seseorang merupakan fitrah dan naluri insani yang tidak bisa diingkari dan sangat dibutuhkan umat manusia, untuk kebutuhan tersebut, Allah mensyariatkan agama yang wajib dipelihara setiap orang, baik yang berkaitan dengan aqidah, ibadah, maupun muamalah.(Muhamad Abu Zahrah, 2010) Adapun kaitanya dikabulkanya putusan ini dilihat dari aspek agama maka, pemohon akan menambah ketakwaanya kepada Allah SWT. Timbulnya akhlak mulia tidak terciptanya perbuatan maksiat. Dalam adanya poligami ini si'ar agama islam semakin luas dikalangan keluarga mereka.

Memeihara jiwa, merupakan hak paling asasi bagi setiap manusia. Dalam kaitan ini, untuk kemaslahatan, keselamatan jiwa dan kehidupan pemohon, maka dalam putusan ini jiwa pemohon akan terjaga dan akan tenang tentram, akan terpenuhinya kebutuhan biologis dengan calon istri yang kedua.

Memelihara akal merupakan sasaran yang menentukan bagi seseorang dalam menjalani hidup dan kehidupannya. Oleh sebab itu, Allah menjadikan pemeliharaan akal itu sebagai suatu yang pokok. Contohnya Allah melarang perbuatan zina maka dalam hal ini pemohon akan terjaga akalnya, pemohon tidak mencari celah dalam menyalurkan hasratnya.

Memelihara kehormatan diri serta keturunan, (Muhamad Abu Zahrah, 2010) karena manusia adalah makhluk mulia, kehormatannya senantiasa dijaga dan dilindungi oleh syariat, serta keturunanya juga oleh Allah SWT. Dalam adanya poligami ini maka keturunan mereka akan terjaga, baik keturunan dari istri pertama atau kedua. Keturunan dari calon istri yang kedua akan terjaga baik karena terpenuhinya kebutuhan hidup dan akan mendapat kasih sayang yang lebih dari keluarga yang baru. (Abror, 2016)

Memelihara harta, manusia tidak bisa hidup tanpa harta. Oleh sebab itu, harta merupakan perlindungan terhadap harta merupakan sesuatu yang pokok dalam kehidupan manusia.(Aprianto, 2017) Untuk mendapatkannya Allah mensyari'atkan berbagai ketentuan dan untuk memelihara harta seseorang allah mensyari'atkan hukuman pencuri dan perampok. Adapun harta bersama yang diajuakan dalam persidangan diantaranya adalah satu unit mobil toyota innova dan satu unit sepeda motor yamaha vixion.(Direktori Putusan Mahkamah Agung Republik Indonesia, 2017) 
Apabila dilihat dari sisi harta putusan tersebut dalam pemisahan harta bersama tidak dikabulkanya maka harta tidak akan terpelihara dengan baik. Karena pemohon kurang bisa menguatkan dalil-dalil dalam persidangan. Maka dalam harta bersama ini akan bisa terjadi penyerobotan atau penguasaan barang berpindah dipihak lain.

Dalam hal ini apabila dikaitkan pada kaidah diatas bahwasanya hakim mempertimbangkan kebaikanya daripada kerusakan yang akan timbul. Yaitu lima dibanding satu. Maslahah lebih diutamakan Jadi pada putusan ini bertujuan untuk memelihara agama, jiwa, akal budi, pemeliharaan kehormatan diri serta keturunan, dan harta kekayaan. (wawancara penanganan perkara, 2019) Maka hanya satu saja yang tidak terpenuhinya yaitu memelihara kekeyaan kemudian hakim mempertimbangkannya dengan dianalogikan empat dibanding satu yaitu lebih besar mendatangkan kebaikan daripada kerusakan. (wawancara penanganan perkara, 2019) Maka hakim mengabulkan izin poligaminya saja sedang permohonan pemisahan harta bersama hakim menolaknya.

Alat bukti surat yang diajukan oleh pemohon terdiri dari 11 alat bukti surat. Pada dasarnya alat bukti surat harus memuat tanda-tanda bacaan yang dimaksud untuk mencurahkan isi hati seseorang dipergunakan pemohon dalam pembuktian. (wawancara penanganan perkara, 2019)

Pemohon dalam pembuktianya mengajukan dua macam alat bukti surat yaitu diamtaranya alat bukti otentik dan alat bukti dibawah tangan. P.1 sampai dengan P.11 semuanya bermeterai cukup kecuali P.5 dan yang fotokopi telah dicocokkan sesuai dengan aslinya sehingga majelis hakim menilai alat bukti tertulis tersebut sah sebagai alat bukti berdasarkan Pasal 1888 kitab Undang-Undang Hukum Perdata dan Pasal 2 Ayat (3) Undang- Undang Nomor 13 tahun 1985 tentang bea meterai serta pasal 2 Ayat (1) Peraturan Pemerintah Nomor 24 Tahun 2000 tentang Perubahan tarif bea meterai dan besarnya batas pengenaan harga nominal yang dikenakan bea meterai.

Pemohon dalam pembuktianya mengajukan dua macam alat bukti surat yaitu diamtaranya alat bukti otentik dan alat bukti dibawah tangan. Alat bukti otentik terdiri surat yang dibuat dihadapan pejabat yang diberi wewenang, dan dalam bentuk menurut ketentuan tanpa bantuan dari pihak lain dan ditempat pejabat itu berwenang. Adapun alat bukti otentik yang diajukan pemohon fotokopi Kartu Tanda Penduduk atas nama pemohon yang dike luarkan oleh Kepala Dinas Kependudukan dan Pencatatan Sipil Kota Madiun, yang telah bermeterai cukup dan bernazegelen serta cocok dengan aslinya (P.1). Fotokopi Surat Keterangan Pengganti KTP atas nama termohon yang dikeluarkan oleh an. Kepala Dinas Kependudukan dan Pencatatan Sipil pemerintah Kota Madiun, yang telah bermeterai cukup dan bernazegelen serta cocok dengan aslinya(P.2). Fotokopi Kutipan Akta Nikah pemohon dan termohon yang dikeluarkan oleh Pegawai Pencatat Nikah Kantor Urusan Agama Kabupaten Madiun, yang telah bermeterai cukup dan bernazegelen serta cocok dengan aslinya (P.3). Fotokopi Kartu 
Received: 2021-01-22 Revised: 2021-01-26 Approved: 2021-01-26

Tanda Penduduk atas nama calon istri kedua yang dikeluarkan oleh Pemerintah Kabupaten Madiun, yang telah bermeterai cukup dan bernazegelen serta cocok dengan aslinya(P.8). Fotokopi Surat Keterangan Kematian (suami calon istri kedua Pemohon) yang dikeluarkan oleh Kepala Desa Kabupaten Madiun, yang telah bermeterai cukup dan bernazegelen serta cocok dengan aslinya (P.11).(Direktori Putusan Mahkamah Agung Republik Indonesia, 2017)

Maka hal ini pertimbangan hukum hakim apabila dikaji dalam teori maslahah maka masuk dalam maslahah mu'tabaroh yaitu, kemaslahatan yang didukung oleh syara'. Dalam akta autentik diajukan dalam persidangan oleh pemohon sudah sesuai dengan Undang Undang dalam hukum acara perdata di Pengadilan Agama. yang dibuat oleh pejabat yang berwenang, dibuat sesuai bentuk yang telah ditetapkan dan dimana pejabat itu berwenang, maka nilai kekuatan pembuktianya adalah bersifat sempurna. (Azhary, 1982)

Jadi kemaslahatan yang dianjurkan oleh syariat dalam alat bukti otentik bisa dianalogikan adanya Undang-Undang yang mengatur secara khusus dalamn pembuktian surat. Maka hakim wajib menerima alat bukti otentik dalam bukti surat yang diajukan oleh pemohon.

Alat bukti yang kedua adalah akta dibawah tangan yang mana akta tersebut dibuat oleh pemohon dan termohon dengan sengaja yang digunakan dalam pembuktian dipersidangan. Dalam maslahah mu'tabaroh akta dibawah tanagan ini sudah sesuai dengan aturan tatacara pemeriksaan bukti surat yang terdiri dari alat bukti P.4, P.6. P.7, P.9 dan P.10. Alat bukti tersebut sudah bernazegelen yaitu sudah bermaterai oleh pejabat pos dan pihak-pihak yang bersangkutan tersebut mengakui akan kebenaran isi dan cara pembuatan akte maka hakim bebas membuktikannya kecuali P. 5 yaitu pembuktian surat tentang harta. bersama pemohon tidak tunduk pada Pasal 8 Ayat (2) dan Pasal 10 UU. No. 13/1985 yaitu tidak bernazegelen oleh pejabat pos juga tidak bermaterai. Pembuktian harta bersama dalam kasus ini adalah tidak dikabulkan oleh majelis hakim meskipun pemohon mengakuinya sebagai harta bersama, tetapi status kepemilikan kendaraan bermotor tidak tunduk pada bukti pengakuan, maka pemohon keberatan menghadirkan buku pemilik kendaraan bermotor dihadapan persidangan dan pemohon tidak bisa menguatkan dalil- dalil permohonan terkait harta bersama dengan alasan BPKB digadaikan terkait mobil innova dan masih dalam proses kredit BPKB motor yahama vixion.(Direktori Putusan Mahkamah Agung Republik Indonesia, 2017) Maka apabila dilihat segi maslahah mu'tabaroh hakim wajib menolaknya karena tidak sesuai dengan tata cara pemeriksaan bukti surat dipersidangan.

Dalam pembuktian saksi pemohon menghadirkan dua orang saksi yang pertama adalah tetangga pemohon sedangkan yang kedua adalah teman pemohon. Apabila dilihat segi syarat formil saksi pertama berumur 57 tahun, sedang saksi kedua berumur 49 tahun sehat tidak ada hubunaga darah, tidak ada hubungan kerja, tidak ada hubungan perkawinan, menghadap dipersidangan dan mengangkat sumpah. (Direktori Putusan 
Mahkamah Agung Republik Indonesia, 2017) maka terpenuhi syarat formil apabila dicocokan pada putusan tersebut.

Pada dasarnya saksi tersebuat harus memberikan keteranagan dimukasidang, saksisaksi yang dihadirkan oleh pemohon adalah orang-orang yang tidak dilarang sebagai saksi dan telah memberikan keterangan secara terpisah di depan sidang di bawah sumpahnya sehingga saksi-saksi tersebut telah memenuhi syarat formil sesuai Pasal 145, 144, dan 147 HIR dan keterangan.

Alat bukti saksi ini dalam kacamata dalam maslahah hajjiyah (kemaslahatan sekunder) yaitu maslahah yang dikandung oleh segala perbuatan dan tindakan demi medatangkan kelancaran, kemudahan, dan kesuksesan bagi kehidupan manusia secara utuh dan menyeluruh. Maslahah hajjiyah yaitu untuk mendukung kebutuhan mendasar kemaslahatan primer.(Azwar, 2016) Jadi dalam hal ini pertanyaan yang diberikan oleh hakim kepada saksi tertuju untuk mencari kebenaran alasan alasan yang diajukan dalam persidangan. Dengan tujuan hakim tidak keliru memutus dengan berdasarkan untuk mendukung kegiatan pada keutamaan kemaslahatan primer.(wawancara penanganan perkara, 2019)

Sedang dalam syarat materil putusan nomor 0020/Pdt.G/2017/Pa.Mn kesaksian masih diragukan karena keterangan saksi didasarkan lebih banyak pada sepengetahuan saja keterangan hakim pada saat wawncara kemarin. Pada dasarnya permasalahan ini bisadikatakan sangat intern. Pada saat persidangan saksi ditanya oleh hakim kesaksian atau keterangan saksi tentang isteri pemohon kurang bisa melayani kebutuhan biologis dan bahwa saksi mengetahui termohon tidak keberatan dan rela dimadu. Saksi tersebut hanya mendapatkan curhatan dari pemohon. (wawancara penanganan perkara, 2019)

Dari syarat materiil yang diragukan tersebut mungkin hakim menggunakan dasar pasal 170 HIR saling bersesuaian satu sama lain. Maslahah hajjiyah Yang berbentuk keringanan untuk mempertahankan dan memelihara kebutuhan mendasar manusia. Dari sisi maslahah hajjiyah perkara nomor 0020/Pdt.G/2017/Pa.Mn sudah sesuai karena jika hakim tidak memutuskan untuk suami berpoligami maka kesulitan akan datang dan tidak akan terpeliharanya tujuan utama kemaslahatan primer. Adanya kemudahan untuk berpoligami dikarenakan suami sendiri kurang dengan kebutuhan biologisnya terhadap istrinya ini akan dan menimbulkan kesulitan karena suami akan tidak bisa merasakan nafkah batin dari istri maka hakim memutuskan untuk berpoligami ini sudah tepat karena guna menghilangkan kesulitan dan memunculkan kemudahan untuk penunjang kemaslahatan primer.

Dikabulkan izin poligami ini maka termohon akan terhindar dari perbuatan yang tidak semestinya. Jadi hakim memberi keringanan mengabulkanya meskipun syarat materiil saksi tidak terpenuhi agar terpenuhinya untuk memelihara Agama, jiwa, akal, keturunan dan harta. 


\section{KESIMPULAN}

Putusan dengan nomor perkara 0020/Pdt.G/2017/PA.Mn sudah sesuai dengan kaidah Maslahah Dzaruriyyah, karena dalam masalah tersebut untuk memelihara agama, jiwa, akal, keturunan dan harta sudah terpenuhi. Hanya satu saja yang belum terpenuhi tentang harta maka maslahah lebih besar harus didahulukan. Terkait dengan alat bukti tertulis secara formil maupun materiil sudah terpenuhi tetapi dalam bukti harta bersama tidak sesuai dengan undang undang maka hakim menolaknya dan sudah sesuai dengan maslahah mu'tabaroh kemaslahatan yang didukung oleh syara'. Alat bukti saksi termasuk maslahah hajjiyah bukti saksi kurang maksimal atau masih diragukan kesaksianya saksi hanya mengetahuinya, hal tersebut tidak sesuai syarat materiil (Pasal $171 \mathrm{HIR} / 308 \mathrm{RBg}$ ) melihat, mendengar, dan mengalami sendiri. Maka hakim memberi keringanan terhadap para pihak dengan tujuan untuk mendukung terpenuhinya pemeliharaan agama, jiwa, akal, keturunan dan harta.

\section{DAFTAR PUSTAKA}

Abror, K. (2016). Poligami Dan Relevansinya Dengan Keharmonisan Rumah Tangga (Studi Di Kelurahan Rajabasa Bandar Lampung). Al-'Adalah.

Adonara, F. F. (2015). Prinsip Kebebasan Hakim dalam Memutus Perkara Sebagai Amanat Konstitusi Principles of Fredom of Justice in Decidene The Case as a Constitutional Mandate. Jurnal Konstitusi.

Aprianto, N. E. K. (2017). Konsep Harta dalam Tinjauan Maqashid Syariah. Journal of Islamic Economics Lariba.

Ardhian, R. F., Anugrah, S., \& Setyawan, B. (2015). Poligami Dalam Hukum Islam Dan Hukum Positif Indonesia Serta Urgensi Pemberian Izin Poligam Di Pengadilan Agama. Privat Law.

Azhary, M. T. (1982). HUKUM ACARA PERDATA DI LINGKUNGAN PERADILAN AGAMA. Jurnal Hukum \& Pembangunan. https://doi.org/10.21143/jhp.vol12.no2.897

Azwar, Z. (2016). PEMIKIRAN USHUL FIKIH AL-GHAZÂLî TENTANG AL-MASLAHAH ALMURSALAH (Studi Eksplorasi terhadap Kitab al-Mustashfâ min 'Ilmi al-Ushûl Karya AlGhazâlî). FITRAH:Jurnal Kajian Ilmu-Ilmu Keislaman. https://doi.org/10.24952/fitrah.v1i1.327

Belakang, A. L. (1974). Undang-Undang Republik Indonesia Nomor I Tahun 1974 Tentang Perkawinan. Mentri/Sekretaris Negara Republik Indonesia.

Direktori Putusan Mahkamah Agung Republik Indonesia. (2017). Putusan Pengadilan Agama Kota Madiun Nomor 0020/Pdt.G/2017/PA.Mn.

Hermanto, A. (2017). ISLAM, POLIGAMI DAN PERLINDUNGAN KAUM PEREMPUAN. KALAM. https://doi.org/10.24042/klm.v9i1.326

Muhamad Abu Zahrah. (2010). Usul fiqih (Saefullah ma'sum (ed.); Terjemah). PT Pustaka Firdaus.

Sugianto, B. (2017). Kedudukan Ahli Waris Pada Perkawinan Poligami. Al-Adl: Jurnal Hukum. wawancara penanganan perkara, (2019). 
Vol. 1 No. 1 (2021): Islamic Science, Culture, and Social Studies

Received: 2021-01-22 Revised: 2021-01-26 Approved: 2021-01-26

Copyright (c) 2021 Izzat Abdika Mukalafin

cc) (7) (5) This work is licensed under a Creative Commons Attribution-NonCommercial 4.0 International License. 